\title{
Marketplace orchestration of taste: Insights from the Bridgewater Hall
}

DOI:

10.1080/0267257X.2016.1187196

\section{Document Version}

Accepted author manuscript

Link to publication record in Manchester Research Explorer

\section{Citation for published version (APA):}

Skandalis, A., Banister, E., \& Byrom, J. (2016). Marketplace orchestration of taste: Insights from the Bridgewater Hall. Journal of Marketing Management, 926-943. https://doi.org/10.1080/0267257X.2016.1187196

\section{Published in:}

Journal of Marketing Management

\section{Citing this paper}

Please note that where the full-text provided on Manchester Research Explorer is the Author Accepted Manuscript or Proof version this may differ from the final Published version. If citing, it is advised that you check and use the publisher's definitive version.

\section{General rights}

Copyright and moral rights for the publications made accessible in the Research Explorer are retained by the authors and/or other copyright owners and it is a condition of accessing publications that users recognise and abide by the legal requirements associated with these rights.

\section{Takedown policy}

If you believe that this document breaches copyright please refer to the University of Manchester's Takedown Procedures [http://man.ac.uk/04Y6Bo] or contact uml.scholarlycommunications@manchester.ac.uk providing relevant details, so we can investigate your claim.

\section{OPEN ACCESS}




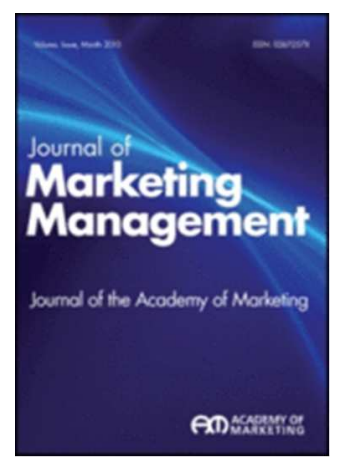

\section{Marketplace orchestration of taste: Insights from the Bridgewater Hall}

\begin{tabular}{|c|c|}
\hline Journal: & Journal of Marketing Management \\
\hline Manuscript ID & RJMM-2015-0257.R2 \\
\hline Manuscript Type: & Special Issue Article \\
\hline $\begin{array}{r}\text { Keywords (headings not } \\
\text { selectable): }\end{array}$ & $\begin{array}{l}\text { Arts \& heritage marketing }<\text { Arts, social and not for profit marketing, } \\
\text { Consumer culture }<\text { Consumer research, Consumer experience }< \\
\text { Consumer research, Identity }<\text { Consumer research }\end{array}$ \\
\hline Methodologies: & ethnography, phenomenology / observation, interviewing \\
\hline Free Response Keywords: & place, taste \\
\hline
\end{tabular}

\section{SCHOLARONE ${ }^{\text {TW }}$ \\ Manuscripts}




\title{
Marketplace orchestration of taste: Insights from the Bridgewater Hall
}

\begin{abstract}
The aim of this paper is to explore how a concert hall can orchestrate and shape individuals' classical music tastes. The paper is based on an eight-month ethnography at the Bridgewater Hall concert venue in Manchester. Our emergent findings illustrate how classical music tastes are influenced via the spatial meanings of the concert hall. These meanings include various physical, historical and socio-cultural aspects that are revealed in the context of the Bridgewater Hall. Our study contributes to various streams of consumer culture theory (CCT) research and opens up avenues for future research on the interrelationships of space and place with taste.

\section{Summary statement of contribution}

Our study focuses on spatial taste orchestration, and provides valuable insights for CCT research into taste and space and place. More specifically, we provide a phenomenological approach to the study of place that moves away from conventional approaches and captures the totality of the meanings captured in the concert hall. Our study also positions the concert hall as an emplaced taste regime that shapes attendees' classical music tastes and their consumption practices within the classical music field. Finally, we illustrate how particular places acquire significance within individuals' everyday lives in the context of classical music consumption.
\end{abstract}

\section{Keywords}

Classical music, consumer culture theory, experiential consumption, place, taste, concert halls Word count: 8,031 (excluding references) 


\section{Introduction}

'Identity is worked and power is wielded within the spaces of musical experience, and few who enter its rarified atmosphere exit unchanged'. (DeChaine, 2002, p. 91)

This study explores the shaping qualities of the places of musical experience, along with their ability to orchestrate musical tastes. In particular, we explore the shaping of individuals' tastes in a concert hall setting within the field of classical music consumption. The logic of this paper broadly concerns an exploration of the interrelationships between space and place with taste. Both space and place and taste have been studied extensively across the humanities and social sciences. However, there is little empirical research that brings together these two theoretical constructs, and investigates how particular places tend to orchestrate and shape taste. Phenomenologically-oriented philosophical thought sees place as the primary basis of our experience with the world (cf. Creswell, 2004). Such philosophers have long argued for a revitalisation of the place construct in contemporary scientific thought. Consumer culture theory (CCT) research (cf. Arnould and Thompson, 2005) has illustrated the importance of space and place in a diversity of ways (e.g. Arnould, 2005; Debenedetti, Oppewal, \& Arsel, 2014; Maclaran \& Brown, 2005). We argue that connecting taste with place can provide novel insights for those fields of marketing theory and practice that deal with the socio-cultural aspects of consumption.

We position our paper within the field of CCT research and borrow insights from such fields and streams of thought as cultural-oriented sociology and the phenomenology of space and place. Using the field of classical music consumption (Bourdieu \& Wacquant, 1992) to establish the socio-cultural positioning of our study, we turn our attention towards the Bridgewater Hall concert venue, a classical and orchestral music oriented concert hall in Manchester, UK; and ask how the meanings of this particular place tend to influence and shape consumers' tastes and identity investments, within this particular field of consumption. 
The paper is based on an eight-month ethnography conducted at the venue. During this period, the first author attended more than twenty classical music concerts in which he kept fieldnotes, gathered artefact material, participated in informal interactions and completed interviews with concert attendees. Our emergent findings indicate how consumers' classical music tastes are shaped and transformed within the Bridgewater Hall via the physical, historical and sociocultural spatial meanings of the place. These findings contribute to an understanding of the role of individuals' place-dependent musical experiences in the orchestration of their classical music tastes, and open up avenues for future research to explore the interplay between space and place with taste. The rest of the paper is organised as follows; first the theoretical foundations of the study are expanded; the context of the study is then presented; methodological procedures are discussed; the findings are presented; and finally, conclusions and implications for CCT research are drawn.

\section{Theoretical Background}

\section{Field, habitus, and taste}

In Bourdieu's (1984) early writings, taste is understood as reflecting the employment of generalised forms of capital such as economic, cultural, social, and symbolic capital. These capitals are stored within an internal system of dispositions, termed habitus, and are acquired as part of consumers' primary socialisation processes. In his later writings, Bourdieu moved towards the abandonment of generalised capital conceptions to replace them with fielddependent ones, that is of capital conceptions that are linked with specific social fields (Bourdieu \& Wacquant, 1992). Field-specific capital is not only acquired as part of consumers' primary socialisation processes but also as part of their participation in various social fields throughout the course of their lives. As such, habitus is continuously developed and re-enacted along with consumers' engagement in different fields of consumption. 
Bourdieuian concepts of taste, habitus, and field have inspired CCT research in a number of different ways. A useful categorisation is provided by Coskuner-Balli and Thompson (2013) who recognise two distinct Bourdieu-inspired analytic trajectories within consumer culture research studies. First, research that is based upon Bourdieu's earlier generalised capital conception attempts to show how consumers' cultural capital investments influence their consumption choices, preferences and tastes (e.g. Allen, 2002; Holt, 1998; McQuarrie, Miller, \& Phillips, 2013; Ustuner \& Thompson, 2012). This stream of research explicates how social class directs the ways in which status-oriented consumption is practiced in a variety of consumption spaces (Saatcioglu \& Ozanne, 2013). Second, research that is supported by Bourdieu's later field-dependent capital conception deals with consumers' membership and involvement within a diverse array of consumption communities (e.g. Arsel \& Bean, 2013; Arsel \& Thompson, 2011; O’Sullivan, 2009; Thornton, 1996). This stream of research focuses on consumers' creation of field-dependent capital through identity investments in particular consumption communities (Coskuner-Balli \& Thompson, 2013). Such studies highlight the move towards more contextualised forms of capital (e.g. Thornton, 1996), yet these efforts largely focus on the structural aspects of taste, quite often deal with class-based and status practices within the consumption fields and/or communities investigated, and ultimately provide a macro-social interpretation of the phenomenon at hand.

A reliance on field and habitus risks failing to take into consideration the reproductive role of human agency, which is grounded in individuals' actions and interactions and ultimately shapes their habitus. Crossley (2001) points towards the embodied potential of phenomenological interpretations of Bourdieu's work. As such, we add a third analytic trajectory of Bourdieu-inspired CCT research which is informed by Crossley (2001) and takes into consideration the most embodied aspects of habitus and taste. There exist only a handful of prior studies that incorporate elements of these considerations. For example, Kerrigan, 
Larsen, Hanratty and Korta (2014) describe how consumers utilise music while running with the aid of mobile music technologies in order to improve their running experience. From a Bourdieuian point of view, the musicalisation of running in their study is achieved through the development of existential capital that unfolds from consumers' running practices (Nettleton, 2013). Saatcioglu and Ozanne (2013) conducted an ethnographic study in the micro-cultural context of trailer parks to uncover the micropolitics of moral-driven consumption and status negotiation. In the context of their study, 'habitus becomes a locally enacted phenomenon that activates multiple dispositions, a set of beliefs, and particular skills, which in turn reflects in the ways consumers navigate the marketplace and larger societal structure' (Saatcioglu \& Ozanne, 2013, p. 708). These studies highlight the most embodied potential of the Bourdieuian concepts of field and habitus which occurs via individuals' actions and interactions and is ultimately grounded in the spatial context within which these (inter)actions take place.

The influence of spatiality on individuals' habitus and tastes remains largely underexplored in CCT research. However, it has not been entirely untouched within the field of cultural-oriented sociology (Benzecry \& Collins, 2014; Lopez-Sintas, Garcia-Alvarez, \& Perez-Rubiales, 2012; Nettleton, 2013). In their microsociological study of 'opera fanatics', Benzecry and Collins (2014) explain how these consumers transcend the structural aspects of taste in favour of a number of in-concert interaction rituals that provide them with authentic opera experiences. Moreover, Lopez-Sintas et al. (2012) found that museum viewers who reported having lived an intense unforgettable aesthetic experience shared two common conditions in their experiences with artworks; the awareness that the artwork viewed was original and that they personally had the necessary contextual cultural capital to interpret its social value. We argue that these two conditions indicate the potentially transformative aspects of taste enacted in arts spaces and the field-specific norms with which these spaces 
abide. Finally, in her ethnographic account of fell running in the English Lake District, Nettleton (2013) develops the concept of existential capital to highlight the gains acquired from the embodied activity of fell running, thus, incorporating the runners' bodily awareness of the various challenging elements (e.g. ground and weather conditions) and their spatial awareness (e.g. spectacular landscapes).

Our study aims to contribute to these lines of work by explicitly investigating the spatial aspects of consumers' tastes. We aim to delve deeper into the spatiality of individuals' field-specific experiences to address the question of how particular consumption places inform habitus and taste. In other words, this paper aims to uncover how the spatial meanings of the Bridgewater Hall orchestrate and shape the habitus and taste of the consumers that participate in the field of classical music consumption. In the next section, we outline the spatial approach adopted in this paper and review previous CCT research that has dealt with issues of space and place.

\section{Theories of space and place}

Place has traditionally been subject to a wide range of definitions and interpretations and the term is often used interchangeably with space. According to Creswell (2004), there are several ways that place has been approached and researched so far. He identifies three distinct approaches namely descriptive, social constructionist and phenomenological. In this paper, we adopt the phenomenological approach which conceptualises place as a way of looking and knowing the world, as the experiential marker of our existence (Bachelard, 1964; Casey, 1998; Tuan, 1977) A phenomenological conception positions place as a platform of action that is physical and historical, social and cultural (Casey, 2001) and argues that we understand the world through our experiences in particular places (Tuan, 1977); such experiences convert space into lived place and mark the distinction between the two concepts. 
The phenomenological approach, therefore, involves us perceiving the world by being emplaced and goes beyond descriptive and social constructionist approaches of place 'to define the essence of human existence as one that is necessarily and importantly in-place' (Creswell, 2004, p. 51). For example, Gaston Bachelard, in his classic piece The Poetics of Space, provides a rich and detailed account of the ways in which a person's house is topoanalytically related with their self and identity (Bachelard, 1964). In short, for Bachelard, houses consist of a set of places (rooms) each one of which invoke memory and imagination (Casey, 1998). In CCT research, a number of scholars have highlighted the need for empirical studies that take into consideration the emplaced aspects of consumer behaviour (e.g. Sherry, 2000) rather than conceptualising place as a static entity which is incorporated into existing social categories, or as a dynamic entity which is socially constructed by its inhabitants. Such conceptualisations are influenced by a social constructionist approach to place and fail to account for the orchestrative qualities of place. We feel that the phenomenological approach to place allows us to fully capture the dynamic and complex nature of place and take into consideration the variety of ways in which it shapes identity and taste.

Prior CCT research has adopted either the descriptive or the social constructionist approach to place generally at the expense of phenomenological considerations, an omission which we now discuss in more detail. Some studies deal with the spatial dimensions of the contemporary marketplace. There are several strands to this stream of CCT research. Firstly, a handful of studies are concerned with broader experiential consumption practices as evidenced in various consumption spaces (e.g. Arnould \& Price, 1993; Celsi, Rose, \& Leigh, 1993; Kozinets, 2002) and are aligned with experiential marketing approaches that emphasise the importance of creating extraordinary consumption experiences which often possess transformative qualities (Arnould \& Price, 1993). We note that the transformative character of these consumption experiences is mainly the result of the extraordinary nature of the context 
in which they occur; be it a high-risk leisure activity (Celsi et al., 1993) or a festival celebration (Kozinets, 2002). The multi-faceted role of place in creating and shaping such experiences remains somehow underexplored. Secondly, an emerging area of consumer culture research deals with the interplay between aesthetics and experiential forms of consumption (e.g. Goulding, 2001; Houston \& Meamber, 2011; Joy \& Sherry, 2003). In particular, Houston and Meamber (2011) discuss the increasing importance of aesthetics in consumer research and their neglected role in the experiential consumption literature. The authors propose that the aesthetic elements of Disney World's EPCOT Center such as the architecture, costumed employees, and live cultural performances contribute to the construction of an 'authentic' world of the past, via individuals' consumption experiences there. Moreover, Goulding (2001) investigates how the museum marketplace enacts a series of consumption experiences that revolve around existential and aesthetic types of nostalgic behaviour, while Joy and Sherry (2003) examine the variety of ways in which the body experiences artworks so as to inform and shape the aesthetic appreciation of consumers and their overall aesthetic experiences in museums. However, in these studies, the aesthetic experience is the primary unit of analysis and any spatial considerations are mostly conceptualised as supportive elements of the aesthetic process. A third strand of research deals with the processes by which consumers develop attachments to particular consumption places (e.g. Debenedetti et al., 2014; Maclaran \& Brown, 2005). Such studies broadly investigate how consumers develop emotional and symbolic bonds with particular places. For example, Debenedetti et al. (2014) consider how place attachment occurs via perceptions of familiarity, authenticity and security and is eventually translated into experiences of feelingat-home. In doing so, they adopt a gift economy perspective to describe how individuals develop attachments with a series of commercial places in France such as bars, restaurants and concert halls. However, these places are treated as elements of the circuit of the gift 
economy process, rather than as key events by themselves Another stream of research deals with the spatial dimensions of contemporary consumer culture in the context of services and retail marketing to construct interpretations of consumption places that transcend existing conceptualisations of place as a marketing mix element (e.g. Arnould, et al., 2009; Kozinets et al., 2002). From a CCT perspective, Arnould (2005) suggests a set of economic, utopian, ludic, and temporal resources that retailers and service providers might employ to transform commercial places so as to reflect consumers' tastes. By adopting a social constructionist approach to place, this stream of research does not fully capture the actual meanings of place as they emerge vis-à-vis individuals' consumption experiences.

In sum, previous CCT research has not yet fully acknowledged the variety of ways in which habitus and taste are interrelated with space and place. In particular, most prior work does not explain how the spatial meanings of particular places orchestrate and shape individuals' tastes and no theoretical framework exists that attempts to address such disparities. The aim of this paper is to redress this literature gap by exploring how the Bridgewater Hall concert venue shapes individuals' classical music tastes. Next, we offer a contextual overview of the classical music field and outline our methodological approach before we move on to discuss our findings.

\section{The field of classical music consumption}

The musical field is by nature highly fragmented and consists of a wide range of music genres, taste communities and regimes (Arsel \& Bean, 2013; Southerton, 2001). A music genre might be defined as 'a system of orientations, expectations, and conventions that bind together an industry, performers, critics, and fans in making what they identify as a distinctive sort of music' (Lena \& Peterson, 2008, p. 254). In this paper, we understand the field of classical music as a field that encompasses such music styles and genres as classical, 
chamber, opera, and symphony; that stand in diametrical opposition to popular music, and traditionally appeal to an older audience. In addition to this, as Larsen, Lawson and Todd (2010) point out, most studies on the socio-cultural aspects of other genres of music consumption focus solely on adolescents or younger adults and further underline the need to investigate the situational aspects that are linked with consumers' music tastes and preferences. A strand of cultural-oriented sociological research has investigated the interrelationships of music with space and place (e.g. Connell \& Gibson, 2003; DeChaine, 2002). DeChaine (2002) argues that in order to be able to understand how music might be shaped by place, it is important to explore the ways in which 'musical space meshes with the specificities of place, in its particular physical, socio-cultural, historical, and political contexts' (DeChaine, 2002, p. 92). Accordingly, Connell and Gibson (2003) discuss the importance of aural architecture and the variety of ways through which music shapes space and vice versa.

In the CCT field, the significance of the concert hall for the classical music field has been highlighted by a number of researchers (e.g. Carú \& Cova, 2005; O’Sullivan, 2009). In the context of classical music concert halls, Carú and Cova (2005) explore the role of service elements in the creation of artistic experiences, including how consumers appropriate various aspects of the concert hall servicescape. Their findings show that service elements facilitate immersion with the artistic experience via a threefold appropriation process which includes activities of nesting (developing familiarity), investigating (gaining knowledge) and stamping (ascribing meaning) and are supported by service providers (Carú \& Cova, 2005). Also, O'Sullivan (2009), in his study of classical music orchestra audiences, positions these orchestras as co-consuming communities that share typical brand community characteristics along with the presence of service performers and a set of temporal characteristics. In doing so, O’Sullivan (2009) explicitly focuses on investigation of the social dimensions of the classical music experience of orchestra attendees. Although these studies account for the 
aesthetic appreciation that results from consumers' immersion with aesthetic or artistic experiences, place mainly unfolds as just one of a number of elements within the immersion process rather than a key event in itself upon which other elements emerge (Carú \& Cova, 2005).

\section{Methodology}

The paper is based on an eight-month ethnography at the Bridgewater Hall concert venue. Access was granted by the hall's management team to the first author, who made his presence and role clear to concert attendees through a researcher identification badge and signage which clearly outlined the scope of the research. During the eight-month period, the first author attended more than 20 classical music concerts, where fieldnotes were compiled and artefact material (leaflets, concert programmes and classical music magazines) were gathered. He also participated in informal interactions and completed twenty unstructured on-site and off-site interviews with concert attendees (McCracken, 1988).

A complex approach to ethnographic inquiry was followed. First, we aimed to explore the emplaced aspects of the classical music concert experience. This required a focus on the place aspects of the Bridgewater Hall along with attendees' lived experiences within it (Casey, 1998). The first author spent a considerable amount of time familiarising himself with the concert hall and its various places, in particular the auditorium, the lounge areas, and other seating areas. Particular attention was paid to the diversity of ways in which concert attendees moved in space and interacted with the place, the service providers and the artists before, during, and after each classical music performance. As part of this process, fieldnotes were completed and artefact material was gathered on a systematic basis. This ethnographic approach was supplemented with informal interactions and interviews with the attendees at 
the concert hall, which further helped to identify the embodied aspects of their concert hall experiences as those were realised at the phenomenological level (Joy \& Sherry, 2003).

The informal interactions were not recorded, yet subsequent notes were made as part of the ethnographic process. However, the unstructured interviews were recorded, transcribed and anonymised. These unstructured interviews were conducted both on and off site, something that we will elaborate on shortly. All interview participants were within the 30-70 year-old age range, supporting observations from previous studies conducted within the classical music field (Larsen et al., 2010). Our analysis did not focus specifically on socioeconomic characteristics, which we argue are beyond the scope and objectives of our study. We followed a combination of purposeful and snowballing sampling techniques, and interviews varied in duration depending on the circumstances under which they were conducted (Kozinets, 2002). More specifically, on-site interviews were conducted based on concert attendees' degree of engagement with classical music and their familiarity with concert hall venues and the Bridgewater Hall. We recruited further participants to be interviewed off-site. Key informants were initially identified during our informal interactions based on their degree of engagement with classical music and degree of familiarity with concert halls, along with their interest in the study. These informants introduced us to further informants who possessed similar characteristics. While brief information about the study was available to all participants (via signage and the researcher), interview participants received specific written information about the purpose of the study and were asked to sign a consent form to confirm their understanding and voluntary participation. Off-site interviews were an average of one hour long, and typically included a more detailed discussion about participants' musical tastes and their relationship with the classical music field which often transcended their lived experiences at the Bridgewater Hall (Thompson \& Haytko, 1997). These 
interviews also helped us to further position our observations within the classical music field in our attempt to ground our experiential themes (Bourdieu \& Wacquant, 1992).

In terms of data analysis and interpretation, a constant comparative process was followed (Glaser \& Strauss, 1967) and we also adopted Spiggle's (1994) steps of coding, categorising, and abstracting in order to be able to be continuously informed by emergent findings and theory in a systematic manner. Fieldnotes, transcribed interview data and artefact material were coded and read in depth several times (Kozinets, 2002). After the initial thematic categories were identified, a revision of the analysis was conducted according to those categories, leading to a process where emergent themes informed previous themes as we went back and forth between data and extant literature (Thompson, Locander, \& Pollio, 1989). The multiple sources of data collection helped us to ensure trustworthiness and confirm and further develop emergent themes.

\section{Findings}

The Bridgewater Hall is Manchester's biggest and most internationally-renowned concert venue and was constructed in 1996 to replace the Free Trade Hall. While the majority of its 250 yearly concerts revolve around classical music, it also puts on performances in other musical genres including rock, pop, jazz and world music (Bridgewater Hall, 2015). In addition, the hall is home to three orchestras, namely the Hallé, the BBC Philharmonic, and the Manchester Camerata. These orchestras are regarded as taste communities within the field of classical music in general, and the Bridgewater Hall in particular. Our emergent findings illustrate how consumers' classical music tastes are orchestrated and shaped within the Bridgewater Hall through the physical, historical and socio-cultural meanings of the concert hall. We present our findings in four thematic categories, namely the spatial politics of 
appreciation, the past and present of the Bridgewater Hall, the aural-driven architecture of the concert hall, and the poetics of the Bridgewater Hall space.

\section{The spatial politics of appreciation}

The spatial politics of appreciation refers to the spatial orchestration of taste in the concert hall. The Bridgewater Hall's resident orchestras act as locality-based taste communities (Southerton, 2001) that nurture institutionalised cultural capital from the classical music field to the Bridgewater Hall and coordinate the aesthetics of classical music practices at the venue (Arsel \& Bean, 2013). Attendees associate themselves with these taste communities by mostly attending concerts only when these orchestras perform. Other attendees voluntarily participate in the various choirs of these orchestras by undertaking vocal coaching, attending regular rehearsals and social events, and even by performing in 'choral recitals'. Long-term engagement with such orchestras contributes to the creation of a sense of belonging and familiarity (Debenedetti et al., 2014). During our interview session, Dan explained his association with the BBC Philharmonic orchestra.

"I remember an early concert at the Bridgewater which might not be long after it opened and my girlfriend at the time and I, went down to see $[\ldots]$ and that was when we first became aware of what a great sound you get in there but also the way that it was a bit extra because of the additional aspects of the performance, the orchestra performance $[\ldots]$ We are very lucky to have quality performances, you know, such a great standard of performance for various reasons. It's interesting that the BBC Phil has always been in Manchester and it's just that we've got that around".

(Dan, 40s, interview)

For Dan, the presence of the BBC Philharmonic orchestra, one of the most renowned classical music orchestras in the United Kingdom, at the Bridgewater Hall complements the physical aspects of the concert hall, i.e. the quality of the sound. By citing their existence in 
Manchester as 'interesting', Dan emphasises the importance of the orchestra's location in Manchester along with its status within the classical music field. For him as well as for other informants, their association with these orchestras is at once spatial and temporal and seems to act as a confirmation of their shared classical music tastes. Such a confirmation is ultimately shaped by the aesthetic nature and positioning of these orchestras, not only within the classical music field but also within the context of the Bridgewater Hall. Here, Jenny elaborates upon her ten-year engagement with the Hallé orchestra choir and the various rehearsals of which she has been part.

"It does make you explore avenues that you might not have explored just on your own because, you know, you are forced to learn this piece [...] through studying it you may actually get to really love it and then you've got a whole new bit of a repertoire opened to you".

(Jenny, 50s, interview)

For her, the Hallé choir represents a platform upon which she not only performs but also shapes her taste through the exploration of classical music pieces with which she is not familiar. As Jenny points out, this shaping process is essentially created via her participation in the choir's rehearsals. In the context of kitchen consumption practices, Southerton (2001) argues that the informants in his study relate to generic social categorisations mainly through their association with locally-based taste communities. Accordingly, we propose that the presence of these resident orchestras in the concert hall provides a direct connection between the attendees and the classical music field, and also leads to the development of a spatial politics of appreciation which further nurture and shape the classical music tastes of our participants.

We further illustrate the variety of consumption practices through which such spatial politics unfold and aesthetic appreciation occurs. For example, the understanding regarding when one is able to enter the auditorium once the performance has started is imposed on the 
audience. The ushers only allow latecomers to enter the hall during gaps between pieces, in order to avoid interruptions to the performance - for the benefit of both the performers and the audience. Other examples of similar consumption practices include considerations such as: the importance of silence in the auditorium during the concert performances; and knowing when to applaud and when to cough.

"It is strange to see how silence is interrupted from clapping after each part of the performance is over, and especially at the end of the performance. Clapping is the ultimate form of appreciation, clapping with passion, clapping loudly, clapping to show one's emotional involvement with the performance" (fieldnote extract, Hallé Extravaganza concert, 4/10/2014)

"Silence is appreciation here and coughing a sign of disrespect, sometimes, a sign of dissatisfaction as well" (fieldnote extract, BBC Philharmonic concert, 7/10/2014)

As evidenced by the above extracts, silence, clapping, and coughing represent contextualised cultural capital practices at the Bridgewater Hall (Allen, 2002; Lopez-Sintas et al., 2012; Saatcioglu and Ozanne, 2013). Our ethnography revealed that each one of these practices refer to various modes of 'in-concert' aesthetic appreciation. Silence and clapping are common positive reactions to the classical music experience, whereas coughing can be perceived as 'a sign of disrespect' towards the audience and the performers - which is often attributed to low cultural capital - or 'a sign of dissatisfaction' towards the classical music performance. However, in delving deeper into the practice of clapping, Jenny further demonstrates inconsistencies in the practice and audience interpretation of the etiquette surrounding it.

“They really don't like it if you clap in-between movements. And I can see the point [..] But it seems to me that some movements, particularly some first movements and some symphonies, 
you just want to applaud after! And, for goodness sake, the conductor has put his arms down and I think it's a shame that people are frowned upon if they burst into spontaneous applause. And if you think if you were at a jazz concert, you'd be applauding that champion soloist even if the other instruments were still playing! I quite like to see a bit of that. But...I think I am a heretic!" (Jenny, 50s, interview)

Jenny's quote highlights the field-dependent nature of the practice of clapping, which, for her, becomes constraining in terms of her classical music experience. She positions herself as a partial outsider referring to the committed Bridgewater attendees as 'they' and herself as 'heretic' for defending 'spontaneous applause'. Jenny acknowledges the spatial politics of appreciation from which the contextualised practice of clapping unfolds and makes comparisons between two distinct musical fields - classical and jazz - based on their differing appreciation conventions. Such contextualised practices are, in some cases, facilitated by the service providers (Carú \& Cova, 2005). Such practices also boost a sense of community within the context of the Bridgewater Hall and might be theorised as quasi-ritualistic behaviours within the collectivised classical music experience at the concert hall (O'Sullivan, 2009).

\section{The past and present of the Bridgewater Hall}

The Bridgewater Hall is located in Manchester city centre, with the square in front of the venue being named after Sir John Barbirolli, one of the Hallé's most famous conductors. His statue also stands outside the main entrance. Our informants revealed that the history of the place and its surrounding urban landscape play an important role in their classical music experiences and the attachment they have created with the hall (Debenedetti et al., 2014). In particular, informants' classical music experiences relate to knowledge and involvement in 
the local history of Manchester's classical music spaces, such as the Free Trade Hall. This building still exists in its past architectural form, in close proximity to the newer venue, and is now home to the Radisson Hotel (Figure 1). Gina illustrates how the attachment that she developed with the Free Trade Hall informs her engagement with classical music and the Bridgewater Hall.

“...And then we were always invited even in junior school which was quite exciting really because we were taken to the Free Trade Hall, because actually this building and where it is at the moment, it wasn't here. Every school used to go to the Free Trade Hall, sometimes it was once a year, sometimes it was twice a year. And I remember being so excited! And that's when I started hearing [classical music]"

(Gina, 60s, interview)

When asked to describe her relationship with classical music and her experiences at the Bridgewater Hall, Gina immediately recalled how she developed her initial interest in classical music through its predecessor. For many informants, the Bridgewater Hall provides a nostalgic connection with the history of the Free Trade Hall, which was the place in which they were first introduced to the classical music field. Gina's quote reveals a nostalgic tone (Goulding, 2001; Houston \& Meamber, 2011). Her present emotional attachment (Debenedetti et al., 2014) with the Bridgewater Hall is shaped by the historical continuity that it provides with its predecessor (DeChaine, 2002).

"I used to attend concerts when the Hallé performed in Belle Vue. Are you aware of the history of the Hallé? Well, during the war, when there was no hall in the town, they used to perform, and for a few years afterwards until the Free Trade Hall was rebuilt, they performed at Belle Vue Circus [...] And as a teenager I used to go to concerts there. Then of course we graduated to the Free Trade Hall and since [then] we got in here”. (Robert, 70s, interview) 
Robert reveals an historical continuity which is firmly positioned within attendees' desire to create romantic links with their past classical music experiences which are spatially informed (Goulding, 2001). For him, Belle Vue 'Circus' (a former zoo and amusement park in Manchester) which was the first place in which the Halle Orchestra performed, and then the Free Trade Hall, effectively narrate, in spatial terms, the history of his relationship with classical music. For Robert, such an historical continuity is associated with the history of the Hallé orchestra in these places and then becomes incorporated into his Bridgewater Hall experience.

In sum, the Bridgewater Hall is perceived as being a key aspect of the history of the classical music landscape in Manchester. We argue that the surrounding historical landscape contributes to the maintenance of this historical continuity. Such continuity helps informants such as Gina and Robert to avoid sensing displacement (Maclaran \& Brown, 2005) whereby the Bridgewater Hall continues the classical music history tradition of Manchester from such places as the Free Trade Hall. As such, our informants develop a spatial form of habitus which is locally enacted from the historical antecedents of the Bridgewater Hall (Saatcioglu and Ozanne, 2013) and informs their classical music experiences. 


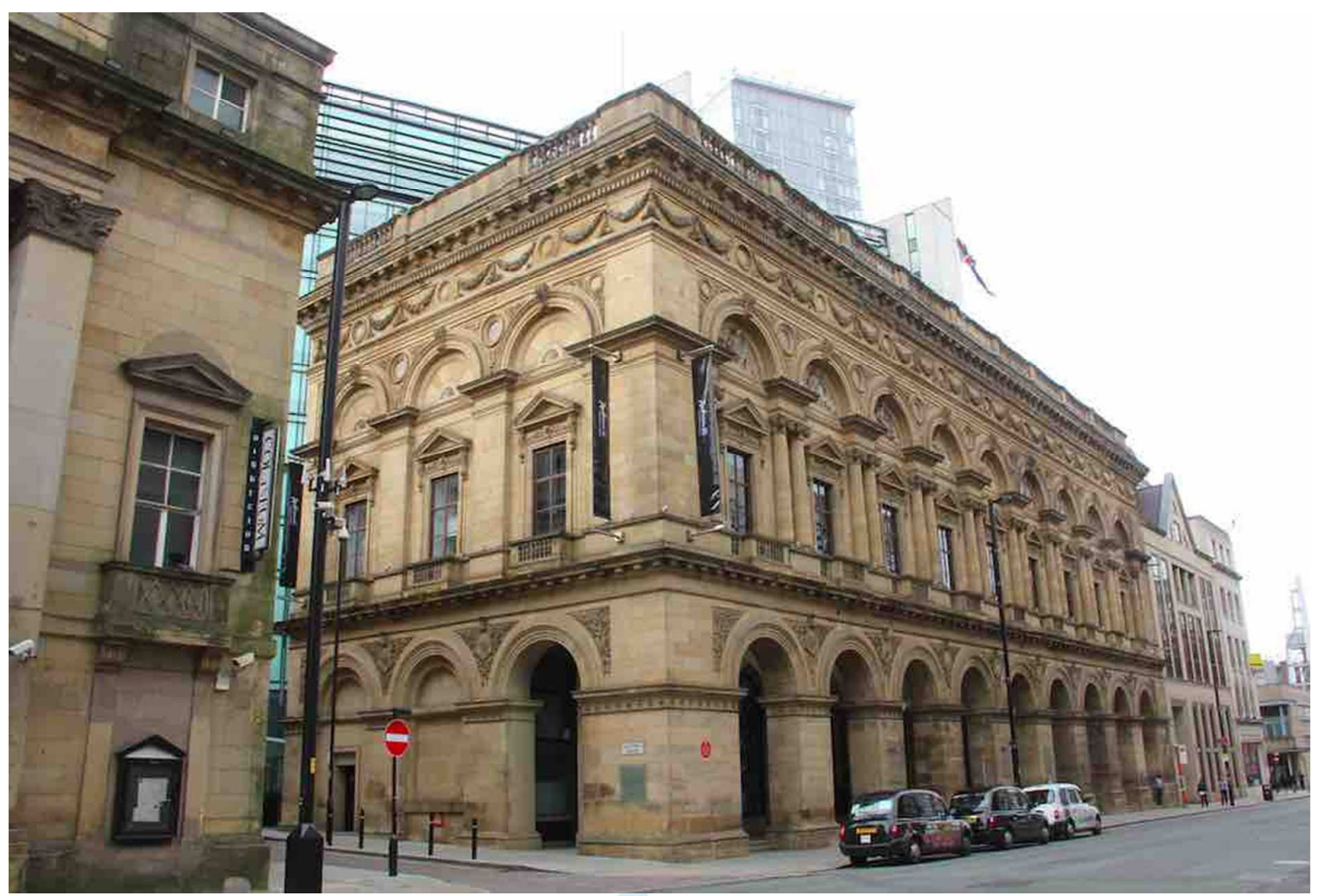

Figure 1. The Free Trade Hall

The aural-driven architecture of the concert hall

In light of the experiential consumption era, previous CCT literature has illustrated that brands tend to draw meaning from the architectural forms of contemporary consumption places (Kozinets et al., 2002). The Bridgewater Hall was built in such a way as to maximise the acoustics. The auditorium features an organ boasting 5,500 pipes, which speak the same sound at each rank, cover the rear wall and further contribute to sound enhancement (Manchester History Net, 2014). The Bridgewater Hall has also been described as one of the quietest musical spaces in the world, with engineering efforts directed towards minimising external sounds; external noise is reduced due to the rubber springs on which the hall is built (BBC News, 2009). The official website of the Bridgewater Hall describes in detail the auraldriven construction process of the concert hall. 
"The Bridgewater Hall is neither concrete nor steel-framed, but is mostly formed from solid, reinforced concrete, moulded and cast like a vast sculpture. This gives it the acoustic ideal of enormous density and mass. The remarkable roof appears to hover, weightless, above the building. One of the most fascinating aspects of the Hall's construction is that the entire structure floats free of the ground on almost three hundred, earthquake-proof isolation bearings or giant springs, so there is no rigid connection between the 22,500 ton building and its foundations. This ensures the Hall's carefully designed acoustic is protected from all outside noise and vibration”. (The Bridgewater Hall website, 5/8/2014)

In order to initiate the attendees into this complex aural architecture, a series of guided tours are frequently organised by the management team, which serve to boost a sense of appreciation of the concert hall acoustics. These guided tours might be considered as spatial resources which are employed to guide attendees towards an acoustic-oriented perception of place (Arnould, 2005). As a result, we argue that the aural architecture of the hall becomes part of the physical aspects of the concert hall servicescape that shapes consumers' classical music experiences there (Carú \& Cova, 2005; Kozinets et al., 2002). It provides a unique sound experience, which has frequently been acknowledged as one of the main factors that provide a satisfying classical music experience (Connell \& Gibson, 2003). One of our informants, Nelly, highlights the importance of the acoustics.

"I've been to loads and loads of concert halls all over the country. I remember going to the Royal Festival Hall when it first opened and the acoustics were absolutely poor in there and they had to do all sorts of alterations in order to make it sound good. So, after a moment this hall started to surprise me really and I've never really been disappointed with any kind of piece that I've listened to".

(Nelly, 50s, interview) 
Nelly communicates her love of the sound of the Bridgewater Hall and compares it with her poor acoustic experiences in previous concert halls such as the Royal Festival Hall. By using terms such as 'surprise' and 'never really disappointed', Nelly aims to highlight the consistent high quality of the acoustics at the Bridgewater Hall. As a result, the quality of the sound does not only constitute a defining factor of attendees' music experiences but is also considered as one of the unique attributes of the spatial character of the Bridgewater Hall. Arthur further demonstrates the significance of this aural-driven architecture of the Hall.

"You see, it's the volume balance that ruins concerts for me and that's the main thing that concerns me [...] I would listen to any type of music in any place, even heavy metal in a cathedral, as long as the acoustic instruments in the metal band were treated the same as the acoustic instruments in a classical group would be treated in that cathedral” (Arthur, 60s, interview)

For Arthur as well as for other individuals with high levels of cultural capital in the classical music field, the 'volume balance' is considered to be a significant aspect of their concert experience, as poor attention to this balance could ruin the natural acoustics of the music instruments and, subsequently, lead to poor sound quality. This need for natural acoustic experiences links with issues of authenticity, which are evidenced in prior research (e.g. Houston \& Meamber, 2011; Lopez-Sintas et al., 2012). In particular, the aural-driven architecture unfolds vis-à-vis attendees' experiences at the Bridgewater Hall which, similar to Houston and Meamber's (2011) museum study, contributes to the delivery of authentic classical music experiences.

The poetics of the Bridgewater hall space 
The poetics of the concert space refer to the fact that each space within the Bridgewater Hall seems to possess its own meaning and function (Bachelard, 1964). The multi-level architecture of the hall gives access to different areas both inside and outside the auditorium such as the gallery, the circle, the choir, and the Barbirolli Room (Figure 2). In their ethnographic study of retail environments, Borghini et al. (2009) explain how different areas within the American Girl Place store give rise to various modes of ideological expression related to the brand at hand. Our ethnography revealed how the different areas of the Bridgewater Hall attract different types of audiences based on their engagement with classical music, their personal preferences and their overall status within the classical music field, along with their familiarity with the concert hall.

"I always have tickets inside gallery so we sit right by the orchestra, so we look right by the orchestra to see what's happening” (Mary, 60s, interview)

"The sound is particularly important but also being able to see for me it's important as well, to see the soloist coming on and being part of the whole interaction really". (Helen, 60s, interview)

As exemplified above, Helen and Mary describe a preference for sitting in the upper section of the auditorium, the 'gallery', which is located above the stage, in order to be able to have a better view of the orchestra and feel as if they are a part of the performance. Benzecry and Collins (2014) have revealed that a series of microcharacteristics of the opera experience shape individuals' cultural consumption and taste patterns. In the Bridgewater Hall, such microcharacteristics acquire a spatial significance which emerges both from their classical music tastes and their degree of familiarity with the concert hall. For example, for attendees with high cultural capital in classical music and with a high degree of familiarity with the concert hall, watching the orchestra perform from 'their own point of view' is a crucial 
element of their concert experience, as in the cases of Helen and Mary. Consequently, this finding also confirms previous CCT research highlighting consumers' locations in concert halls as crucial aspects of their classical music experiences (Carú \& Cova, 2005).

We further illustrate how the location of consumers inside the concert place is shaped by their degree of familiarity with the place and their degree of involvement with classical music. As part of the ethnographic process, we were able to identify several types of attendees that demonstrate how familiarity with the place is intermingled with classical music tastes at the concert hall. The fieldnote extracts below further elaborate on this observation.

"Most of them [the attendees] today seem to have been here before many times. They move into space with confidence and show familiarity as if it [the Bridgewater Hall] is a third space for them where they exercise their musical tastes" (fieldnote extract, London Sinfonietta concert, 3/07/2014)

“And they don't look like they have a particular relationship with classical music. Most of them [the attendees] seem to be outsiders. And you can say both from the clothes they wear, their behaviour at the hall, even by the way they move around the space" (fieldnote extract, Cheshire Choir concert, 18/06/2014)

In the first extract, the type of attendee portrayed encompasses a high degree of familiarity with the concert hall. While individuals who are familiar with the Bridgewater Hall do not necessarily possess high levels of cultural capital in classical music, low familiarity with the concert hall appeared to be most commonly associated with low levels of cultural capital in classical music. As the second extract illustrates, individuals who attend concerts which do not involve purely classical music oriented orchestras, such as the Cheshire Choir, tended to be less familiar both with the Bridgewater Hall and classical music in general. Our discussion of various types of attendees suggests that that the multi-level architecture of 
the concert hall, along with individuals' movement into space, illustrate how aesthetic appreciation becomes embodied in the context of the Bridgewater Hall. In alignment with Joy and Sherry's (2003) study of the ways in which corporeal movements inform consumers' aesthetic experiences, we also indicate that the spatial arrangement of the concert hall further shapes our attendees' classical music experiences.

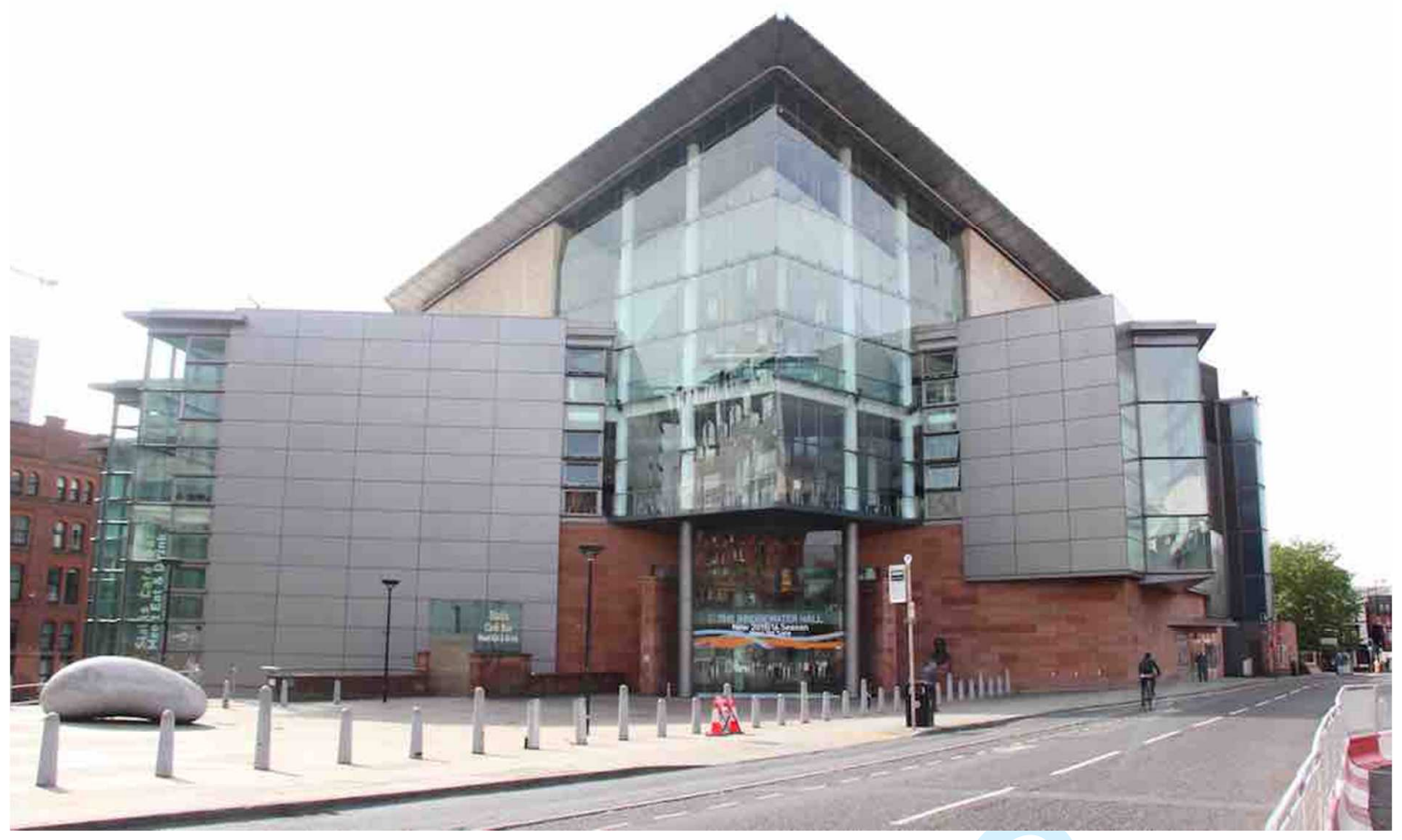

Figure 2. The multi-level architecture of the Bridgewater Hall

\section{Discussion}

The aim of this paper has been to explore how the meanings of the Bridgewater Hall concert venue orchestrate and shape individuals' tastes within the field of classical music consumption. Our findings illustrate how classical music tastes are influenced and moulded by the spatial meanings of the Bridgewater Hall. These meanings include the historical 
antecedents of the concert hall, its aural architecture, the manner in which the concert space is experienced, and the presence of various orchestras within the concert venue that act as local taste communities. More specifically, our findings suggest that the Bridgewater Hall plays an important role in shaping consumers' classical music tastes via the physical, historical and socio-cultural meanings of the place.

This study comes with several theoretical implications for CCT research (Arnould \& Thompson, 2005). To begin with, it provides a somewhat alternative understanding of the concept of place that moves away from conventional understandings and is inspired by a phenomenological approach to place (Creswell, 2004). We argue that this approach enabled us to develop a holistic interpretation of the concert hall which transcends descriptive and social constructionist approaches and captures the totality of the physical, socio-cultural, and historical meanings of the place (Casey, 1998; 2001). Thus, we contribute to previous studies that have considered issues of space and place in the CCT field by showing how the concert hall turns into a platform of action upon which consumers not only perform but also shape their classical music tastes. Specifically, we extend previous CCT research, which focused on habitus and taste and arguably did not account for the spatial dimensions of taste (e.g. Allen, 2002; Arsel \& Bean, 2013; Arsel \& Thompson, 2011). Our study sheds light on the situational and contextual aspects of consumers' tastes (Larsen et al., 2010; Saatcioglu \& Ozanne, 2013). The concert hall can be parallelised with an emplaced taste regime that shapes attendees' classical music tastes and their consumption practices within the classical music field (Arsel $\&$ Bean, 2013). In this respect, although the field-specific cultural capital of our informants is primarily acquired by their overall participation in the classical music field (Allen, 2002), it is also further developed by their specific engagement with, and attachment to, the Bridgewater Hall (Saatcioglu \& Ozanne, 2013). 
In line with alternative conceptualisations of the embodied qualities of habitus and taste (Crossley, 2001), we further propose that our informants developed a spatial form of habitus that possesses 'placial' qualities (Bachelard, 1964; Casey, 1998). The concert hall attendees are not solely influenced by the local context of their consumption behaviour (Benzecry \& Collins, 2014; Saatcioglu \& Ozanne, 2013) and the embodied aspects of their consumption practices (Kerrigan et al., 2014; Nettleton, 2013); rather, the Bridgewater Hall becomes a central pillar of their classical music tastes via the gamut of spatial meanings of the concert hall. These spatial meanings range from the existence of local taste communities to the ways individuals consume the sound architecture of the concert hall, and how they move into space and perceive its historical background. In this sense, our findings also suggest that the Bridgewater Hall consumption experience possesses 'shaping' qualities which remain firmly positioned within the realm of the everyday and the structural terrain of the classical music field. Such a consumption experience cannot be regarded as extraordinary in the sense that it has been defined and studied so far in CCT research (Arnould \& Price, 1993; Celsi et al., 1993; Kozinets, 2002). We argue that this is mainly due to the nature of the Bridgewater Hall itself and its ability to invoke a series of spatial meanings which are inextricably linked with the field of classical music (Borghini et al., 2009). Thus, we also extend prior work on aesthetics and consumption experiences (Goulding, 2001; Houston \& Meamber, 2011; Joy \& Sherry, 2003) by illustrating how these spatial meanings inform attendees' classical music experiences in the concert hall.

\section{Conclusions}

In sum, this study represents an initial effort to portray the interrelationships of space and place with taste. We believe this is a promising area of research which remains underexplored in the CCT literature. We have aimed to highlight how a given place can 
orchestrate and shape individuals' tastes. In doing so, we revealed how the spatial meanings of the Bridgewater Hall influence the classical music tastes of its participants. Our study contributes to existing understandings of place by following a phenomenological approach to the study of place that moves away from conventional approaches predominantly used in CCT research. Our study also contributes to existing theories of taste by illustrating how classical music tastes are spatially orchestrated in the context of the Bridgewater Hall. Finally, our findings can also be considered as useful guidelines that might contribute to the development of experiential design strategies. Future research might aim to further elaborate on the variety of ways in which particular places are connected with, shape, and transform individuals' tastes.

\section{References}

Allen, D. (2002). Towards a theory of consumer choice as a socio-historically shaped practical experience: The fits-like-a-glove (FLAG) framework. Journal of Consumer Research, 28, 515-532.

Arnould, E. (2005). Animating the big middle. Journal of Retailing, 81(2), 89-96.

Arnould, E., \& Price, L. (1993). River magic: Extraordinary experience and the extended service encounter. Journal of Consumer Research, 20, 24-45.

Arnould, E. \& Thompson, C. (2005). Consumer culture theory (CCT): Twenty years of research. Journal of Consumer Research, 31(4), 868-882.

Arsel, Z., \& Bean, J. (2013). Taste regimes and market-mediated practice. Journal of Consumer Research, 39(, 899-917.

Arsel, Z., \& Thompson, C. (2011). Demythologizing consumption practices: How consumers protect their field-dependent identity investments from devaluing marketplace myths. Journal of Consumer Research, 37, 791-806. 
Bachelard, G. (1964). The poetics of space. Boston, MA: Beacon Press.

BBC News (2009). The quietest room in the world. Retrieved from http://news.bbc.co.uk/local/manchester/hi/people_and_places/newsid 8224000/8224555.stm.

Benzecry, C., \& Collins, R. (2014). The high of cultural experience: Toward a microsociology of cultural consumption. Sociological Theory, 32, 307-326.

Borghini, S., Diamond, N., Kozinets, R., McGrath, M., Muniz, A., \& Sherry, J. (2009). Why are themed brandstores so powerful? Retail brand ideology at American Girl Place. Journal of Retailing, 85, 363-375.

Bourdieu, P. (1984). Distinction: A social critique of the judgement of taste. Cambridge, MA: Harvard University Press.

Bourdieu, P., \& Wacquant, L. (1992). An invitation to reflexive sociology. Chicago, IL: Chicago University Press.

Bridgewater Hall (2015). About the Hall. Retrieved from http://www.bridgewaterhall.co.uk/about-the-hall/the-bridgewater-hall/.

Carú, A., \& Cova, B. (2005). The impact of service elements on the artistic experience: The case of classical music concerts. International Journal of Arts Management, 7(2), 39-54.

Casey, E. (1998). The fate of place: A philosophical history, Berkeley, CA: University of California Press.

Casey, E. (2001). Between geography and philosophy: What does it mean to be in the placeworld? Annals of the Association of American Geographers, 91, 683-693.

Celsi, R., Rose, R., \& Leigh, T. (1993). An exploration of high-risk leisure consumption through skydiving. Journal of Consumer Research, 20, 1-23.

Connell, J., \& Gibson, C. (2003). Soundtracks: Popular music, identity, and place, London: Routledge. 
Coskuner-Balli, G., \& Thompson, C. (2013). The status costs of subordinate cultural capital: At-home fathers' collective pursuit of cultural legitimacy through capitalizing consumption practices. Journal of Consumer Research, 40, 19-41.

Creswell, T. (2004). Place: A short introduction. Oxford: Blackwell.

Crossley, N. (2001). The phenomenological habitus and its construction. Theory and Society, 30, 81-120.

Debenedetti, A., Oppewal, H., \& Arsel, Z. (2014). Place attachment in commercial settings. Journal of Consumer Research, 40, 904-923.

DeChaine, R. (2002). Affect and embodied understanding in musical experience. Text and Performance Quarterly, 22, 79-98.

Glaser, B., \& Strauss, A. (1967). The discovery of grounded theory: Strategies for qualitative research. Chicago, IL: Aldine.

Goulding, C. (2001). Romancing the past: heritage visiting and the nostalgic consumer. Psychology \& Marketing, 18, 565-592.

Holt, D. (1998). Does cultural capital structure American consumption? Journal of Consumer Research, 25, 1-26.

Houston, R., \& Meamber, L. (2011). Consuming the "world": reflexivity, aesthetics, and authenticity at Disney World's EPCOT Center. Consumption Markets \& Culture, 14, 177-191. Joy, A., \& Sherry, J. (2003). Speaking of arts as embodied imagination: A multisensory approach to understanding aesthetic experience. Journal of Consumer Research, 30, 259-282.

Kerrigan, F., Larsen, G., Hanratty, S., \& Korta, K. (2014). 'Gimme shelter': Experiencing pleasurable escape through the musicalisation of running. Marketing Theory, 14, 147-166.

Kozinets, R. (2002). Can consumers escape the market? Emancipatory illuminations from Burning Man. Journal of Consumer Research, 29, 20-38. 
Kozinets, R., Sherry, J., DeBerry-Spence, B., Duhachek, A., Nuttavuthisit, K., \& Storm, D. (2002). Themed flagship brand stores in the new millennium: Theory, practice, prospects. Journal of Retailing, 78, 20-38.

Larsen, G., Lawson, R., \& Todd, S. (2010). The symbolic consumption of music. Journal of Marketing Management, 26, 671-685.

Lena, J. \& Peterson, R. (2008). Classification as culture: types and trajectories of music genres. American Sociological Review, 73, 697-718.

Lopez-Sintas, J., Garcia-Alvarez, E., \& Perez-Rubiales, E. (2012). The unforgettable aesthetic experience: The relationship between the originality of artworks and local culture. Poetics, 40, 337-358.

McCracken, G. (1988). The long interview. Newbury Park, CA: Sage.

Maclaran, P., \& Brown, S. (2005). The center cannot hold: Consuming the utopian marketplace. Journal of Consumer Research, 32, 311-323.

McQuarrie, E., Miller, J., \& Phillips, B. (2013). The megaphone effect: Taste and audience in fashion blogging. Journal of Consumer Research, 40, 136-158.

Manchester History Net (2014). Bridgewater Hall. Retrieved from http://manchesterhistory.net/manchester/tours/tour6/bridgewaterhall.html.

Nettleton, S. (2013). Cementing relations within a sporting field: Fell running in the English Lake District and the acquisition of existential capital. Cultural Sociology, 7, 196-210.

O’Sullivan, T. (2009). All together now: A symphony orchestra audience as a consuming community. Consumption Markets \& Culture, 12, 209-223.

Saatcioglu, B., \& Ozanne, J. (2013). Moral habitus and status negotiation in a marginalized working-class neighborhood. Journal of Consumer Research, 40, 692-710.

Sherry, J. (2000). Place, technology, and representation. Journal of Consumer Research, 27, $273-278$. 
Southerton, D. (2001). Consuming kitchens: Taste, context, and identity formation. Journal of Consumer Culture, 1, 179-203.

Spiggle, S. (1994). Analysis and interpretation of qualitative data in consumer research. Journal of Consumer Research, 21, 491-503.

Thompson, C., \& Haytko, D. (1997). Speaking of fashion: Consumers' uses of fashion discourses and the appropriation of countervailing cultural meanings. Journal of Consumer Research, 24, 15-42.

Thompson, C., Locander, W., \& Pollio, H. (1989). Putting consumer experience back into consumer research: The philosophy and method of existential phenomenology. Journal of Consumer Research, 16, 133-147.

Thornton, S. (1996). Club cultures: Music, media, and subcultural capital, Cambridge: Polity. Tuan, Y. F. (1977). Space and place: The perspective of experience. Minneapolis, MN: University of Minnesota Press.

Ustuner, T., \& Thompson, C. (2012). How marketplace performances produce interdependent status games and contested forms of cultural capital. Journal of Consumer Research, 38, 796814. 